\title{
Cáncer de cuello uterino. Estado actual de las vacunas frente al virus del papiloma humano (VPH)
}

\author{
M. D. Diestro Tejeda, M. Serrano Velasco, F. Gómez-Pastrana Nieto
}

\section{Resumen}

El carcinoma invasor de cuello uterino es una enfermedad de transmisión sexual causada por el virus del papiloma humano (VPH). Entre las nuevas opciones de prevención y tratamiento del carcinoma de cérvix se incluyen la citología en medio líquido, el test de ADN de VPH y las vacunas preventivas y terapéuticas. Las vacunas preventivas frente a VPH están basadas en la producción de VLPs o partículas similares al virus. Existen dos tipos de vacunas: la vacuna bivalente VPH 16 y 18, y la tetravalente VPH 6, 11, 16 y 18. El desarrollo de las vacunas terapéuticas se encuentra aún en experimentación. Actualmente y en las próximas décadas estaremos ante uno de los descubrimientos más importantes de la medicina actual: la prevención y tratamiento de un cáncer mediante vacunación.

Palabras clave: Cáncer de cuello uterino. Virus del papiloma humano (VPH). Vacunas.

Oncología, 2007; 30 (2):42-59 


\section{Summary}

Invasive cervix uteri carcinoma is a sexual transmission disease caused by VHP. Among the new prevention and treatment options of uterine neck carcinoma are cytology in liquid medium, HPV DNA test, and preventive and therapeutic vaccines. The preventive vaccines for HPV are based on the production of virus-like particles (VLPs). There are two types of vaccines: a bivalent for HPV 16 and 18, and a tetravalent for HPV 6,11, 16 and 18. The development of these therapeutic vaccines are still under investigation. With the possibility of cancer vaccination we are facing one of the most important discoveries of the present time medicine.

Key words: Cervical cancer. Human papilloma virus (HPV). Vaccines.

El carcinoma invasor de cuello uterino afecta a mujeres relativamente jóvenes, y su origen inicial es una enfermedad de transmisión sexual causada por el VPH. El virus utiliza el epitelio escamoso para su síntesis e integración celular, originándose una respuesta inmune. Básicamente los virus de bajo riesgo originan lesiones escamosas intraepiteliales de bajo grado (LSIL), mientras que los de alto riesgo pueden producir lesiones de alto grado (HSIL) y, en último término, transformación neoplásica de la unión escamocolumnar. Los factores implicados en esta progresión son dependientes tanto del virus como de los hábitos del huésped.

El método de cribado de cáncer de cuello de útero ha sido la citología cervicovaginal, aunque comienzan a realizarse en la práctica clínica otros procedimientos como citología en medio líquido y test de ADN de VPH. Entre las nuevas opciones de prevención y tratamiento del carcinoma de cérvix se incluyen las vacunas preventivas y terapéuticas. El objetivo de este trabajo ha sido realizar una amplia revisión bibliográfica de la asociación etiológica entre el cáncer de cuello de útero y el VPH, el desarrollo y situación actual de las vacunas preventivas frente a VPH, y la consideración de las vacunas terapéuticas en un futuro próximo.

\section{Epidemiología}

\section{Epidemiología del cáncer de cuello uterino}

El cáncer de cuello uterino es el segundo cáncer más frecuente en mujeres después del de mama en el mundo ${ }^{1}$, y el quinto de todos los cánceres. La edad media de diagnóstico es de 48 años, aunque aproximadamente el $47 \%$ de las mujeres con carcinoma invasivo de cérvix se diagnostica antes de los 35 años. Solo el $10 \%$ de los diagnósticos se hacen en mujeres mayores de 65 años. El tipo histológico más común es el carcinoma de células escamosas, que representa el $80 \%$ de todos los carcinomas invasivos de cérvix ${ }^{2}$.

El $83 \%$ de los cánceres de cérvix diagnosticados cada año ocurren en los países en vías de desarrollo ${ }^{3}$, siendo el mismo la causa más frecuente de muerte por cáncer en estos países, y teniendo una supervivencia media tras el diagnóstico de 5 años, mientras que en los países desarrollados es de 10 años $^{2}$ (Figura 1).

Las cifras estimadas para mujeres mayores de 15 años indicarían que actualmente hay 27 millones de mujeres con displasia de bajo grado, 1,5 millones con displasia de alto grado y 400.000 con carcinoma invasor de cuello ${ }^{4}$.

En España, el cáncer invasor de cuello uterino es el sexto más frecuente, constituye el $4,8 \%$ de los cánceres en la mujer ${ }^{5}$, una de las tasas más bajas del mundo, entre 3,4 y 12,2 casos por 100.000 mujeres $/ a^{n} o^{6}$. La incidencia se ha mantenido constante en los últimos 15 años (1983-1997), aunque analizando por edades, se observa un aumento de incidencia para las mujeres nacidas entre los años 30-40 ${ }^{7}$. La tasa de mortalidad es de 2,7 por 100.000 mujeres/año, semejante al promedio europeo $^{8}$. 


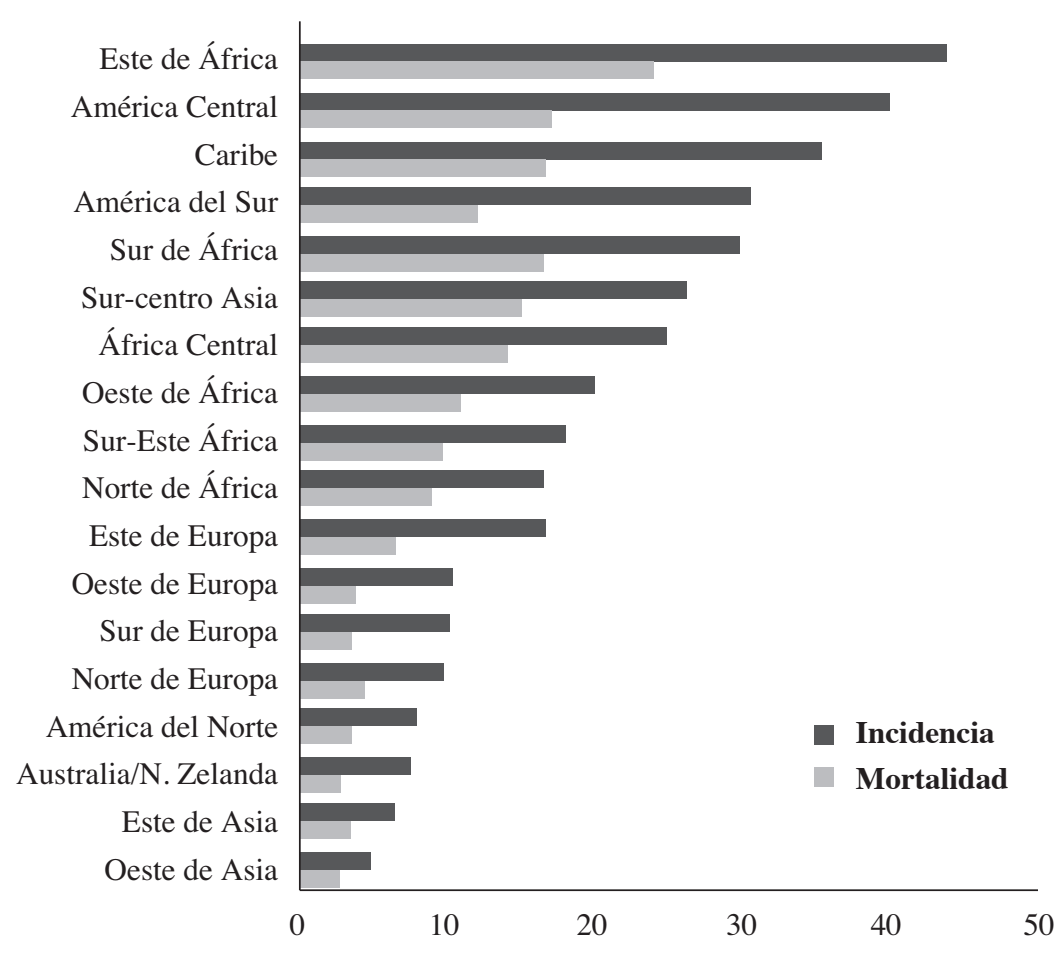

Tasa estandarizada por edad por 100.000 mujeres/año

Figura 1. Tasas de incidencia y mortalidad anual por cáncer invasivo de cérvix en diferentes regiones del mundo (IARC/ Globocan 2000).

Tasas estandarizadas por edad acordes con la distribución de la población mundial en 1960.

Fuente: Franco EL, et al. $2005^{33}$.

\section{Epidemiología del VPH}

El VPH representa la infección de transmisión sexual más frecuente. A escala mundial, es el responsable de un 5,2\% de todos los tumores humanos, correspondiendo un 2,2\% a los países desarrollados, y un 7,7\% a los países en vías de desarrollo ${ }^{9}$. El 70$80 \%$ de las mujeres y los hombres sexualmente activos, han estado expuestos al virus en algún momento de su vida ${ }^{10,11}$.

Se estima la existencia de 310 millones de portadoras de VPH, de las cuales 27 millones corresponderían a condilomas acuminados y 68.400 casos de cáncer de vulva, vagina, ano, pene y cavidad orofaríngea ${ }^{4,9}$.

La prevalencia de VPH en la población femenina es inferior al $10 \%$ en países desarrollados y ligeramente superior al $15 \%$ en países en vías de desarro$1 \mathrm{lo}^{12}$. Según los datos de la Agencia Internacional de Investigación en Cáncer (IARC), se observa que la prevalencia de VPH varía según las áreas geográficas, siguiendo una distribución similar a la de la prevalencia de cáncer de cérvix ${ }^{13-17}$.

Se han realizado varios estudios entre 1992 y 2006 que analizan la prevalencia en España de VPH de alto riesgo oncogénico en mujeres con citologías cervicovaginales normales, en los cuales la prevalencia varió entre el 3,4 y el $17 \%{ }^{18-22}$.

En un estudio realizado en Reino Unido sobre 1075 mujeres de edades similares, se detectó un riesgo acumulado de cualquier infección por VPH en 3 años del $44 \%$, elevándose al $60 \%$ en 5 años, siendo el VPH 16 el tipo más frecuente ${ }^{23}$.

En España, Font y cols estudiaron a 1.383 mujeres atendidas en una consulta de planificación familiar de Barcelona, observando una incidencia de nuevas infecciones del $2 \%$ anual a lo largo de un seguimiento de 3 años. El 50\% de las mujeres con ADN para VPH positivo a la entrada del estudio, dió resultados negativos transcurridos 367 días $^{20}$. 


\section{Cáncer invasor de cuello de útero}

\section{Factores determinantes y cofactores}

Estudios realizados con técnicas de biología molecular de alta sensibilidad y con muestras biológicas adecuadas, detectan VPH de alto riesgo en prácticamente el $100 \%$ de los casos de carcinoma escamoso de cérvix. Para HSIL se detecta en el 70-90\% de los casos y en un 50-70\% para LSIL. La detección para células epiteliales escamosas de significado incierto (ASCUS) es cercana al 50\% ${ }^{24,25}$.

La asociación observada entre VPH y cáncer de cérvix, está entre las más consistentes de las identificadas en cancerología humana, existiendo un consenso creciente en calificarla como causa necesaria, pero insuficiente, ya que no todas las infecciones por VPH persisten o progresan a carcinoma de cérvix $^{1,24,26}$. Los factores determinantes que conocemos para que esta progresión ocurra, son:

1. Factores dependientes del virus:

- Tipo viral.

- Persistencia de la infección en exámenes repetidos.

- Carga viral por unidad celular (probable).

2. Factores ambientales:

- Anticoncepción hormonal oral. Cuando se consumen durante cinco años o más, aunque el riesgo tiende a desaparecer en los 5 años siguientes a la interrupción del consumo ${ }^{27}$.

- Paridad. Cuando se tienen más de 5 embarazos a término. Este factor junto con el anterior, sugieren una asociación positiva entre VPH y esteroides ${ }^{27}$.

- Tabaquismo. Se han aislado sustancias carcinogénicas presentes en el tabaco en el moco cervical, aunque no se conoce bien la dinámica de la interacción ${ }^{2-29}$.

- Edad de la primera relación sexual. Es un conocido factor de riesgo. La prevalencia de VPH más alta comprende las edades inmediatas al inicio de las relaciones, y responde a los patrones de comportamiento sexual de la comunidad ${ }^{1}$. En grupos de edad de 15 a 25 años, si tienen compañeros sexuales distintos, llega a tener prevalencias del 30-40\%. Después de este pico, le sigue una disminución muy marcada, estabilizándose en edades de 25 a 40 años en un 3-10\%, interpretándose esta cifra como una me- dida indirecta del número de mujeres portadoras crónicas de la infección viral, y por tanto, del grupo de alto riesgo para progresión neoplásica. En algunas poblaciones se ha observado un segundo pico de prevalencia en mujeres postmenopáusicas, postulándose que fuera el reflejo de una reactivación de una infección latente y que se asociaría a la reducción fisiológica de la inmunidad natural con la edad ${ }^{4}$.

- Coinfecciones. La Chlamydia trachomatis parece ser un cofactor que actúa por inducción de inflamación crónica y metabolitos mutagénicos ${ }^{30,31}$. El Herpes simple tipo 2 también parece actuar como cofactor, con una evidencia algo más dudosa ${ }^{32}$.

- Deficiencias nutricionales y bajos niveles de antioxidantes son otros factores propuestos ${ }^{18}$.

- Conducta sexual de la población. El contagio por el virus se produce piel a piel ${ }^{33}$. Los lugares más susceptibles de invasión viral son aquellos donde se producen procesos de rápida replicación y diferenciación celular, como la zona de transformación escamocolumnar del cérvix (más activa aún en mujeres jóvenes) y la línea pectínea anal, desarrollando displasias y neoplasias en estas localizaciones. El preservativo, se ha comprobado que es un factor protector, pero no de forma total, para el contagio y adquisición de lesiones precursoras ${ }^{34}$. Parece que la circuncisión masculina también es un factor protector ${ }^{35}$.

El VPH también se relaciona con el cáncer de vulva. Este tipo de cáncer responde a dos modelos etiológicos. El primero ocurre en mujeres menores de 50 años, está ligado a infección por VPH y cursa con lesiones precursoras como neoplasia vulvar intraepitelial de alto grado (VIN II-III). El segundo tipo se produce en mujeres mayores de 50 años, es independiente de la infección viral y no cursa con lesiones precursoras. La fracción de casos atribuible a VPH sería aproximadamente un $50 \%{ }^{36}$.

Otras localizaciones expuestas al virus donde también se pueden producir neoplasias, serían el pene, la vagina y la cavidad oral y orofarínge.

Finalmente, la prevalencia de VPH en mujeres dedicadas a la prostitución sería del $48 \%$ en Japón, del $50 \%$ en Méjico y del 61,6\% en España $^{37-39}$. 
- Situación social. Aquí incluimos a las personas con nivel socioeconómico bajo, las que están en prisión (con prevalencias en España de VPH positivo hasta del $46 \%$ ) y las que provienen de países que no tienen sistemas de cribado (en un estudio realizado en Barcelona se detectó en extranjeras de diversas procedencias una prevalencia de VPH del 14,3\%, en comparación con las españolas del 2,7\%) ${ }^{40,17}$.

- Estado inmunológico. Además de la pérdida de inmunidad natural con la edad ${ }^{3}$, los polimorfismos del complejo mayor de histocompatibilidad (HLA) y del gen supresor tumoral p53 son otros determinantes inmunológicos de susceptibilidad $^{41}$.

Especial consideración merece el papel del virus de la inmunodeficiencia humana (VIH), como muestran los estudios en los que se detectó que en mujeres VIH positivas el riesgo de infección por VPH de alto y bajo riesgo sería de entre 1,8 y 2,7 veces superior con una persistencia 1,9 veces mayor ${ }^{42}$.

\section{Características del virus del papiloma humano}

\section{Genoma viral}

Existen aproximadamente 100 tipos de virus del papiloma humano, de los cuales, 30 ó 40 infectan regular o esporádicamente el tracto genital ${ }^{43}$.

El genoma viral es pequeño, consta de una doble cadena de ADN de 8.000 pares de bases y contiene un máximo de 8 genes, 2 de los cuales son los que codifican las proteínas estructurales o late-proteins L1 y L2 ${ }^{44}$. La partícula viral L1 se dispone en pentámeros, en cuyo centro se acopla L2. Los otros 6 genes codifican proteínas no estructurales o earlyproteins E1, E2, E4, E5, E6 y E7 (Figura 2). Cada nuevo tipo de VPH puede considerarse como tal, si su secuencia en la región L1 del genoma difiere en más de un $10 \%$ de un tipo de VPH previamente descrito $^{45}$.

A su vez, se subdividen en grupos de alto y bajo riesgo oncogénico. Dentro de los de alto riesgo, cabe destacar los tipos 16 y 18 , que juntos se estima son responsables de aproximadamente el $70 \%$ de los casos de cáncer de cuello invasivo ${ }^{46}$, y que están en más del 50\% de los carcinomas basalioide y verrucoso de vulva y pene, y de vagina, y en más del $50 \%$ de carcinomas de ano ${ }^{47}$. A éstos les siguen en frecuencia los tipos 31, 33 y 45, y después el $35,51,52,58$ y $59^{2,48}$. Estos virus también se detectan en las lesiones intraepiteliales de alto y bajo grado.

Entre los tipos de VPH de bajo riesgo, hay que destacar el 6 y 11, que cursan predominantemente con condilomas acuminados y papilomatosis laringea $^{4}$ (Tabla I).

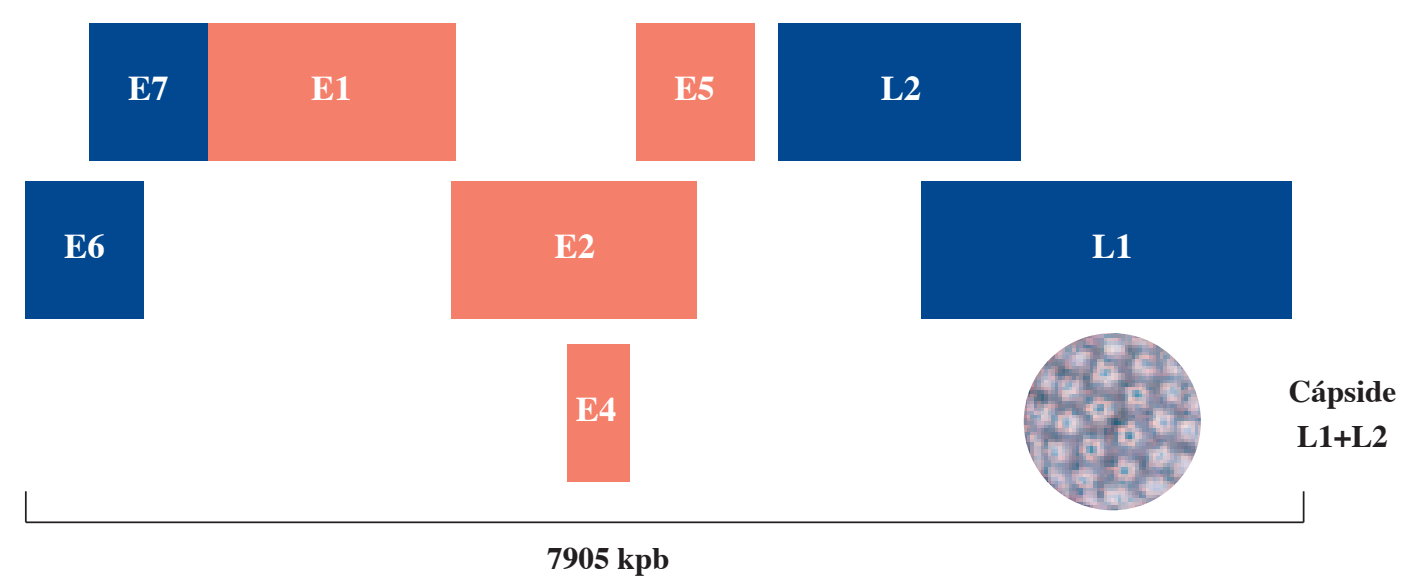

Figura 2. Genoma del VPH.

Los genes E "early” están implicados en la replicación viral (E1 y E2), control transcripcional de la expresión genética (E2), regulación del ciclo celular (E6, E7 y E4) y evasión de la respuesta inmune (E5). Los genes L "late" codifican las proteínas de la cápside viral: L1 es la mayor que se autoensambla configurando pentámeros, y L2 es la menor que se dispone en el centro de dichos pentámeros. 
TABLA I

Virus del papiloma humano: tipos patógenos y enfermedades relacionadas

\begin{tabular}{|c|c|c|c|}
\hline \multirow[t]{2}{*}{ Tipo viral } & \multicolumn{2}{|c|}{ Tipos de VPH } & \multirow[t]{2}{*}{ Enfermedades asociadas } \\
\hline & Vacuna & No vacuna & \\
\hline \multicolumn{4}{|l|}{ Cutáneos } \\
\hline Bajo riesgo & & & Verrugas plantares y cutáneas. \\
\hline Alto riesgo & & & Epidermodisplasia verruciforme. \\
\hline \multicolumn{4}{|l|}{ Mucosos/Cutáneos } \\
\hline \multirow{3}{*}{ Bajo riesgo } & 6 & & Condilomas acuminados. \\
\hline & & $42,43,44,55+$ & Papilomatosis laríngea. \\
\hline & $\begin{array}{l}>90 \% \text { de los } \\
\text { condilomas }\end{array}$ & & Tumor de Buschke-Loewenstein. \\
\hline \multirow[t]{3}{*}{ Alto riesgo } & 16,18 & $31,33,45$ & Verrugas planas, enfermedad de Bowen. \\
\hline & $>70 \%$ de los & $26,35,39,51,55$ & Displasia y carcinoma cervical. \\
\hline & cánceres cervicales & $52,56,58,59,66,68$ & $\begin{array}{l}\text { Carcinoma de pene, vulva, vagina, ano y } \\
\text { orofaringe. }\end{array}$ \\
\hline
\end{tabular}

\section{Patogénesis y ciclo viral}

Cuando se produce una erosión o microtrauma en la capa superficial de los epitelios diana, se facilita que el virus pueda penetrar en las células de la capa basal, donde amplifica su genoma, expresando las proteínas E1, E2, E6 y E7 ${ }^{49}$. En las capas intermedias, vemos que tanto células como virus se replican en tandem, sin haber amplificación de las copias del virus y con poca expresión de los genes anteriores. En las capas superiores, donde el epitelio es diferenciado, el virus se amplifica sin replicación celular, llegando a haber 1000 copias del genoma viral por célula. En este momento, comienzan a expresarse los genes de las proteínas estructurales (L1 y L2), así como el de la proteína E4, produciéndose el ensamblaje de la cápside del virus ${ }^{50}$ (Figura 3 ).

El virus infecta la célula, produciendo lesiones en un periodo de tiempo que puede durar de semanas a meses, induciendo una replicación viral en la que no hay viremia detectable, ya que las células diana finales son los queratinocitos diferenciados ${ }^{10,47,51}$. Estas células están destinadas a descamarse en el estrato superficial del epitelio, donde no se producen señales de peligro obvias que alerten al sistema inmune, por lo que las lesiones no van acompañadas de inflamación ${ }^{47}$.

Anticuerpos circulantes contra la proteína viral de la cápside L1 son detectables tras la infección, con tendencia decreciente en las 2-3 semanas siguientes, manteniéndose niveles bajos de anticuerpos estables y detectables a lo largo del tiempo ${ }^{47}$. La seroconversión confiere inmunidad tipo-específica frente a futuras infecciones, habiéndose descrito cierto grado de inmunidad cruzada entre tipos virales ${ }^{4,52}$.

La inmunidad celular contra la infección viral es crítica en el control y aclaramiento del VPH y, por tanto, en el desarrollo, persistencia y/o progresión de las lesiones displásicas ${ }^{53}$. Las células de Langerhans son las encargadas de presentar los antígenos virales a los queratinocitos, produciéndose una respuesta inmune contra la infección ${ }^{54}$.

La duración media estimada de la infección para los virus de alto riesgo es de 8 a 12 meses, aunque los tipos 16 y 18 tienden a persistir por periodos más prolongados, entre 16 y 24 meses $^{4}$. El $90 \%$ de las infecciones por VPH son benignas, subclínicas y autolimitadas, y gran proporción de infecciones se asocian con displasias de bajo grado que regresan espontáneamente ${ }^{17,55,56}$. Los LSIL pueden ser causados tanto por virus de alto como de bajo riesgo. La infección cervical persistente (definida como detección del virus más de una vez, en un intervalo igual o mayor a 6 meses), es producida por tipos virales de alto riesgo y es el más importante factor de riesgo para progresión a displasia de alto grado ${ }^{57}$.

Según un estudio realizado en Costa Rica, con resultados similares a los de otros países desarrolla- 


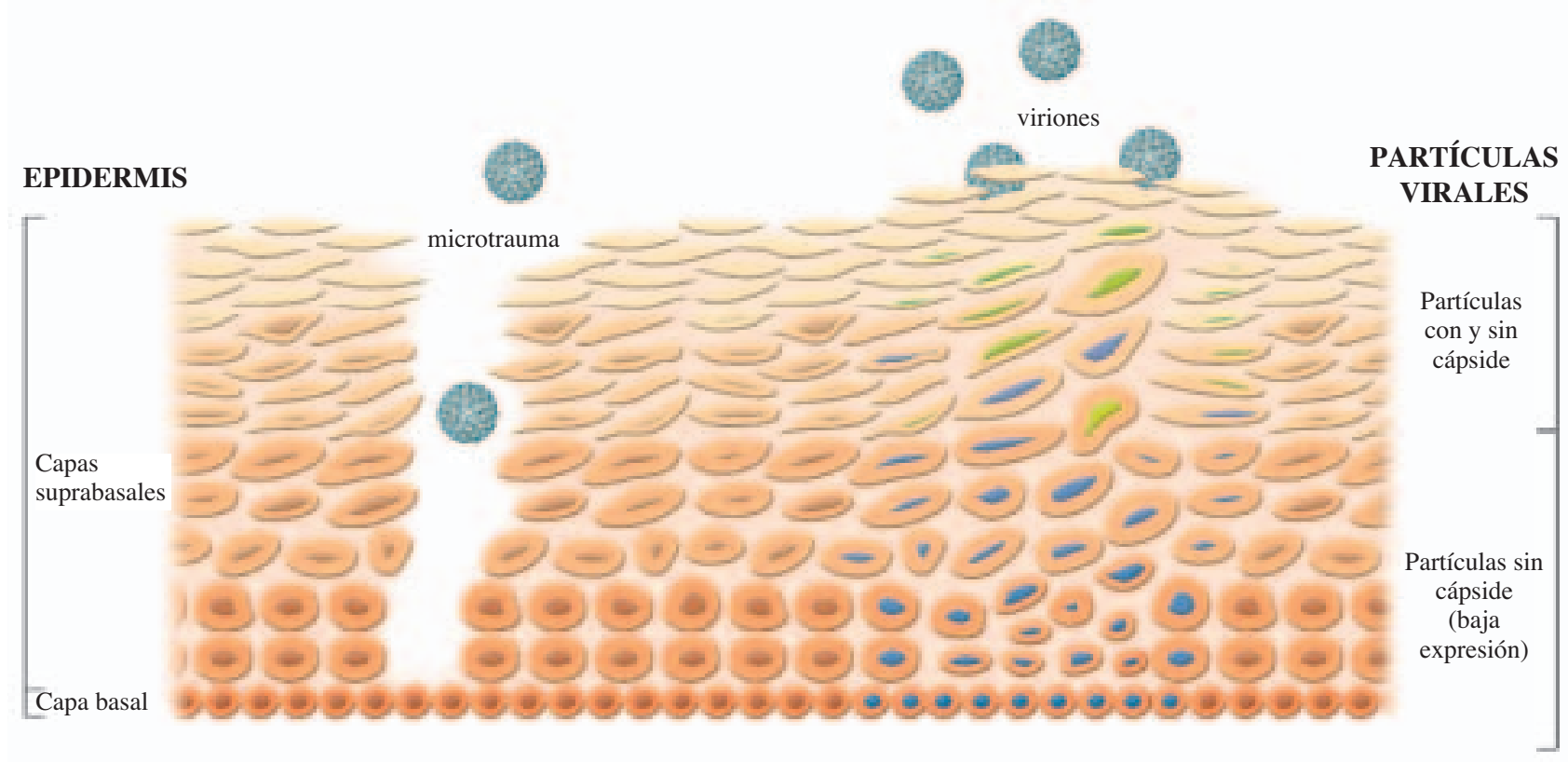

Figura 3. Ciclo vital del papilomavirus.

Un microtrauma en las capas suprabasales del epitelio de la unión escamocolumnar facilita la infección del virus en las capas basales, permaneciendo en situación episómica, con baja expresión. La replicación y expresión viral se produce en las capas superiores, induciendo alteraciones en el epitelio que incluyen papilomatosis, paraqueratosis y coilocitosis. Las nuevas partículas virales se liberan con la descamación de las células más superficiales y diferenciadas del epitelio escamoso.

Fuente: Lowy DR, et al. $2006^{83}$. Reproducido con autorización

dos, las infecciones por VPH 16 y 18 que progresaron a CIN-3 fueron un 17,7 y $13,6 \%$ respectivamen$\mathrm{te}^{57,58}$. Esto se refleja en la curva de incidencia de $\mathrm{VPH}$, en la que tras el pico inicial a los 20 años aproximadamente hay una gran caída de la misma, 10 años después se produce el pico de incidencia de lesiones premalignas (LSIL que progresa a HSIL) y 10-20 años después (a los 40-50 años de edad) se sitúa el pico de incidencia de cáncer de cérvix, ocasionado por aquellos virus que crearon una infección persistente ${ }^{59}$ (Figura 4).

El mecanismo oncogénico mejor conocido por el que actúan estos virus es el que se produce a partir de la síntesis de las oncoproteinas E6 y E7, que se ligan a las proteínas producidas por los genes supresores p53 y $\mathrm{Rb}$ respectivamente, degradándolas e inutilizándolas funcionalmente. Esta interacción en un epitelio inestable como es el de la unión escamocolumnar, conduce a una inestabilidad genómica, aumentando la probabilidad de producir mutaciones específicas ${ }^{4}$.

Los virus de bajo riesgo permanecen en el núcleo de la célula infectada en situación episómica, mientras que los de alto riesgo ejercen su actividad oncogénica integrándose en el genoma celular, con la consecuente progresión a displasias de alto grado. Ocasionalmente existirían mecanismos oncogénicos adicionales en los que el virus no estaría integrado en el genoma celular ${ }^{53}$.

\section{Cribado del cáncer de cuello uterino}

La aplicación de los programas de cribado realizada de forma eficaz, ha demostrado ser efectiva en la reducción de la incidencia y mortalidad por cáncer de cuello uterino en todo el mundo, aunque ninguno ha logrado erradicar totalmente la enfermedad ${ }^{60,61}$.

\section{Citología cervicovaginal}

Es el método de cribado utilizado clásicamente. Tiene una alta especificidad (85-100\%), pero una sensibilidad subóptima y variable $(30-90 \%)^{61}$. La frecuencia de falsos negativos puede ascender hasta el $50 \%$ para lesiones de bajo grado y entre 6-45\% para las de alto grado ${ }^{62}$. La cobertura del cribado influye notablemente en los resultados, y el adenocarcinoma, por su localización endocervical, escapa 


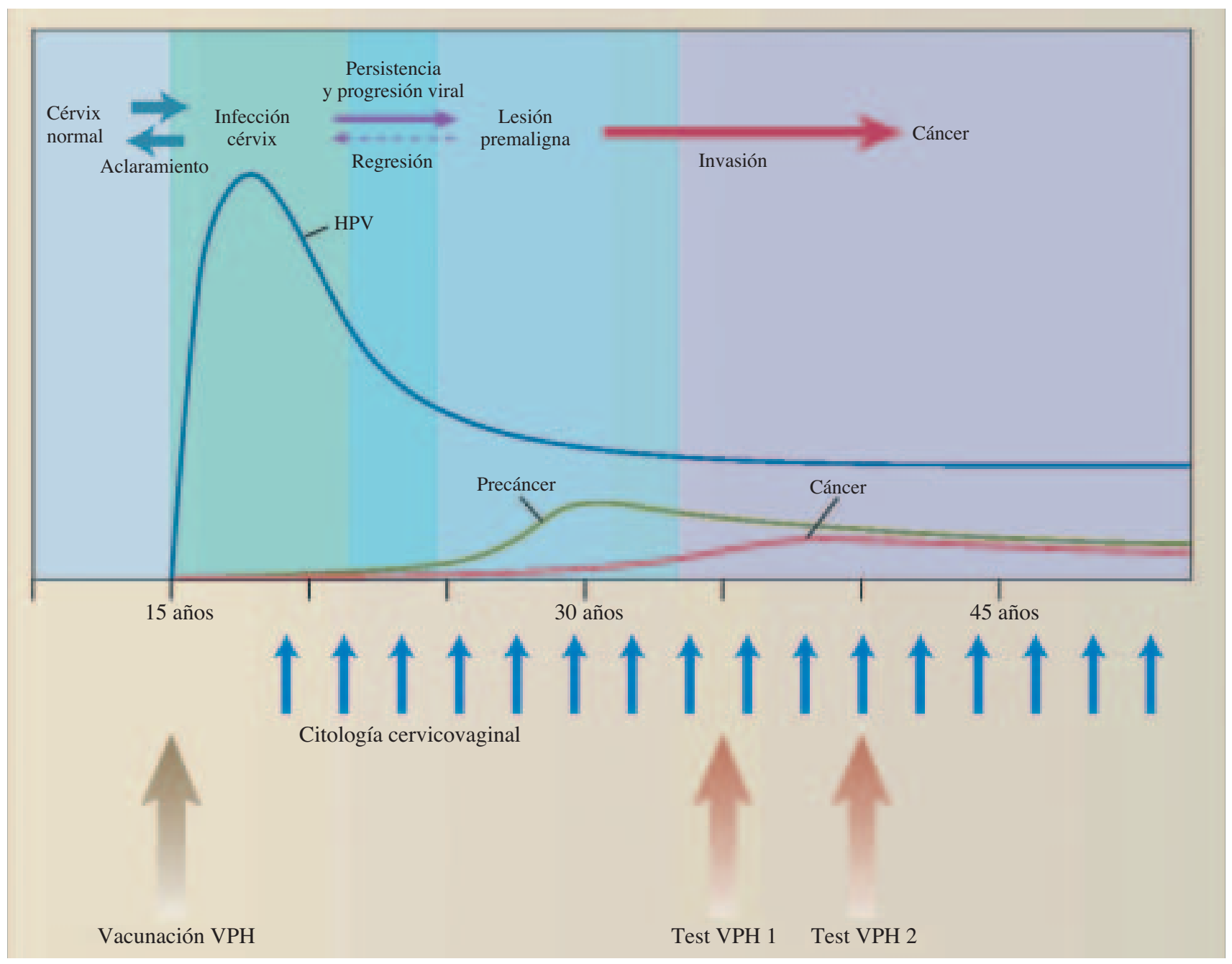

Figura 4. Historia natural de la infección por VPH y cáncer de cérvix.

Las curvas muestran el pico de prevalencia de infección por VPH al inicio de las relaciones sexuales (entre 15 y 20 años de edad), el de lesiones premalignas (10 años después) y el de cáncer invasivo (a los 40-50 años de edad). En la parte inferior, se indican los métodos de prevención basados en citología cervicovaginal, y las estrategias alternativas: vacunación en la adolescencia antes del inicio de las relaciones sexuales y test de detección de VPH en el pico de edad de lesiones premalignas y de cáncer en fase precoz.

Fuente: Schiffman M, et al. $2005^{108}$. Reproducido con autorización

más fácilmente al muestreo ${ }^{63}$. Se conoce, que alrededor de un $80 \%$ de las mujeres que han desarrollado un carcinoma invasor de cuello, no se les había realizado examen citológico previo ${ }^{64}$.

La edad recomendada para iniciar el cribado citológico es a los 3 años del primer coito vaginal, o a los 25 años. La frecuencia más aceptada para la repetición es a los 3 ó 5 años, tras 2 exámenes anuales con resultados normales, en pacientes que no tengan factores que incrementen el riesgo ${ }^{65}$.

La cobertura del cribado en España es alta, y ha aumentado en el último quinquenio ${ }^{66}$. Según la En- cuesta Nacional de Salud del 2003, el 63\% de las mujeres de 20 ó más años, reconoce haberse hecho alguna vez una citología, y sube al $81 \%$ entre los 35 y 45 años $^{46}$.

La colposcopia tiene una tasa de falsos negativos del $10 \%$, llegando los falsos positivos hasta el $90 \%{ }^{62}$. Más reciente, es la introducción de otros métodos como citología en medio líquido, que además permite la detección de VPH sin necesidad de un nuevo muestreo y la reducción de la ratio ASCUS/LSIL en un 55\% y de las muestras insatisfactorias en un $73 \%{ }^{67}$. 


\section{Test de tipificación de VPH}

Este test se está introduciendo como sustituto o complemento de la citología cervicovaginal. La sensibilidad de la prueba es sistemáticamente superior a la de la citología para la detección de lesiones de alto grado (mejoría de la detección de un 28\%). La homogeneidad de los resultados es significativamente superior a la de la citología. Sin embargo, la especificidad de la citología es superior en un $7 \%{ }^{68}$.

El excelente valor predictivo negativo de la determinación viral nos es muy útil en la práctica, porque si no se demuestra virus, la posibilidad de que se esconda una lesión de alto grado es muy remota $^{69}$. En poblaciones donde los programas de cribado citológico son adecuados, es aconsejable utilizar la detección de VPH en caso de duda (ASCUS o LSIL), o para distanciar las citologías en mujeres mayores de 30 años con bajo riesgo para contraer la infección; pero en aquellas donde aún los programas de cribado son deficitarios, como en países subdesarrollados, se está valorando introducir la técnica como cribado primario, con procedimientos de automuestreo ${ }^{70}$.

La mayoría de los métodos de detección de VPH, están basados en la detección de $\mathrm{ADN}^{45}$. Es posible realizar el análisis patológico y molecular de VPH a partir de una misma muestra. El procedimiento se puede realizar mediante test de captura de híbridos (sondas ARN-ADN viral) o por métodos de amplificación de secuencias diana mediante reacción en cadena de la polimerasa (PCR) ${ }^{71}$.

\section{Vacunas profilácticas frente a VPH}

Demostrado el origen viral del cáncer de cuello uterino, se han abierto nuevas e interesantes opciones en la prevención y tratamiento de las lesiones asociadas a $\mathrm{VPH}^{2}$. Las líneas de investigación epidemiológicas a seguir incluirían: modificación y ampliación de los programas de cribado y tipificación del VPH, desarrollo de programas de vacunación profilácticas y terapéuticas, y nuevos tratamientos inmunomoduladores (interferón e imiquimod) y antivirales ${ }^{71-73}$.

Próximamente comenzarán a aplicarse las primeras vacunas profilácticas frente a VPH en varios países. Quedan cuestiones por resolver en cuanto a la aplicación del programa de vacunación y su efecto sobre la incidencia y mortalidad por carcinoma cervical invasivo ${ }^{2}$.

Los primeros ensayos clínicos preliminares en humanos comienzan en la década de los 90 , con el descubrimiento y síntesis de las partículas semivirales o partículas similares al virus (Virus like particles $V L P S)^{47,74-78}$. Demostrada la seguridad y la respuesta inmunitaria de las vacunas profilácticas de VPH, se iniciaron ensayos clínicos aleatorizados para cuantificar su eficacia y efecto a largo plazo ${ }^{52,79-82}$.

\section{Partículas similares al virus (L1 y L2 "virus-like particles")}

La mayor dificultad en la investigación de vacunas profilácticas contra VPH, ha sido la imposibilidad de reproducir el proceso de crecimiento epitelial y diferenciación en cultivos celulares, por lo que la replicación del virus in vitro no es posible ${ }^{77}$. Una vacuna VPH atenuada, que contiene ADN oncogénico, supondría demasiado riesgo para su aplicación en humanos ${ }^{74}$. Por tanto, en la prevención primaria frente a VPH, se utilizan vacunas constituidas por subunidades virales sintetizadas mediante ingeniería genética $^{83}$.

El fundamento básico de la producción de vacunas profilácticas es la producción de la proteína estructural L1, mediante la introducción del gen de la misma en cultivos de células eucariotas y, posteriormente, la capacidad de autoensamblarse formando unas estructuras tridimensionales vacías llamadas VLPs. Son proteínas recombinantes, morfológicamente idénticas a los viriones VPH originales, pero no contienen genes virales, por lo que no pueden causar infección ${ }^{52,75,76,84,85}$. La vacuna puede incluir las partículas L1 o bien L1 más L2 ${ }^{86}$ (Figura 5).

\section{Tipos de vacunas profilácticas}

En los ensayos clínicos avanzados fase III, las vacunas preventivas basadas en la proteína L1 VPH han sido las siguientes ${ }^{83,85,87}$ :

a. Vacuna bivalente VPH 16 y 18 . Sintetizada gracias a un sistema de expresión celular de un baculovirus, combinado con un compuesto de aluminio más lípido A monofosforilado (AS04), que permite protección e inducción de altos y prolongados títulos de anticuerpos, 
además de un aumento de la inmunidad mediada por células ${ }^{85}$. El protocolo de administración sería a los 0,1 y 6 meses $^{83,88-90}$.

b. Vacuna tetravalente VPH 6, 11, 16 y 18. Preparada mediante una proteína recombinante sintetizada en levaduras, administrada también con un compuesto alumínico convencional. Pauta de vacunación 0,2 y 6 meses ${ }^{83,89}$.

La vacuna VPH se administraría inicialmente en tres dosis intramusculares a las adolescentes de 12 años, requiriendo dosis de recuerdo a los 10 ó 20 años, según protocolos. El efecto protector se prolongaría más allá de diez años de la dosis de recuerdo ${ }^{79,91}$.

La mayoría de los efectos secundarios fueron de intensidad leve o moderada. El más frecuente fue reacción en el lugar de inyección, que cursó con dolor, tumefacción y enrojecimiento. El síntoma sistémico más común fue cefalea, aunque sin significación estadística frente a placebo ${ }^{74,82,88,90}$.

\section{Respuesta inmunológica}

Existen evidencias en los múltiples ensayos realizados, de que la vacuna VPH genera una respuesta inmunológica específica a base de anticuerpos neutralizantes de las proteínas de la cápside viral ${ }^{2,47,83}$. Koutsky publica un $99,7 \%$ de seroconversión tras la administración de la vacuna L1 VLP VPH 16, con títulos sesenta o cien veces superiores respecto a las mujeres infectadas de manera natural ${ }^{52,79,91,92}$.

Con la profilaxis primaria, tras el pico inicial de anticuerpos circulantes, se observa una disminución de hasta diez veces en el título a los dos años de seguimiento. Después el nivel de anticuerpos neutralizantes Ig G permanece estable en el tiempo, y asegura alta protección frente a la infección por VPH a los 5 años de administración de la vacuna ${ }^{82}$. Sólo el $50 \%$ de las pacientes inmunizadas desarrollan anticuerpos locales en la mucosa vaginal frente a $\mathrm{VPH}^{2,93-96}$.

Existirían además otros mecanismos de neutralización viral mediada por inmunidad celular, aún no bien establecidos ${ }^{92,94,96,97}$. En el ensayo de Giannini, la vacuna produciría la estimulación de células presentadoras de antígenos y la inducción de citoquinas como factor de necrosis tumoral $\alpha$ (TNF- $\alpha$ ) e interleukina 12 (IL-12), que activarían las células T helper. Esta memoria inmunológica celular aseguraría la protección a largo plazo frente a la infección por $\mathrm{VPH}^{85,88,90}$ (Figura 5).

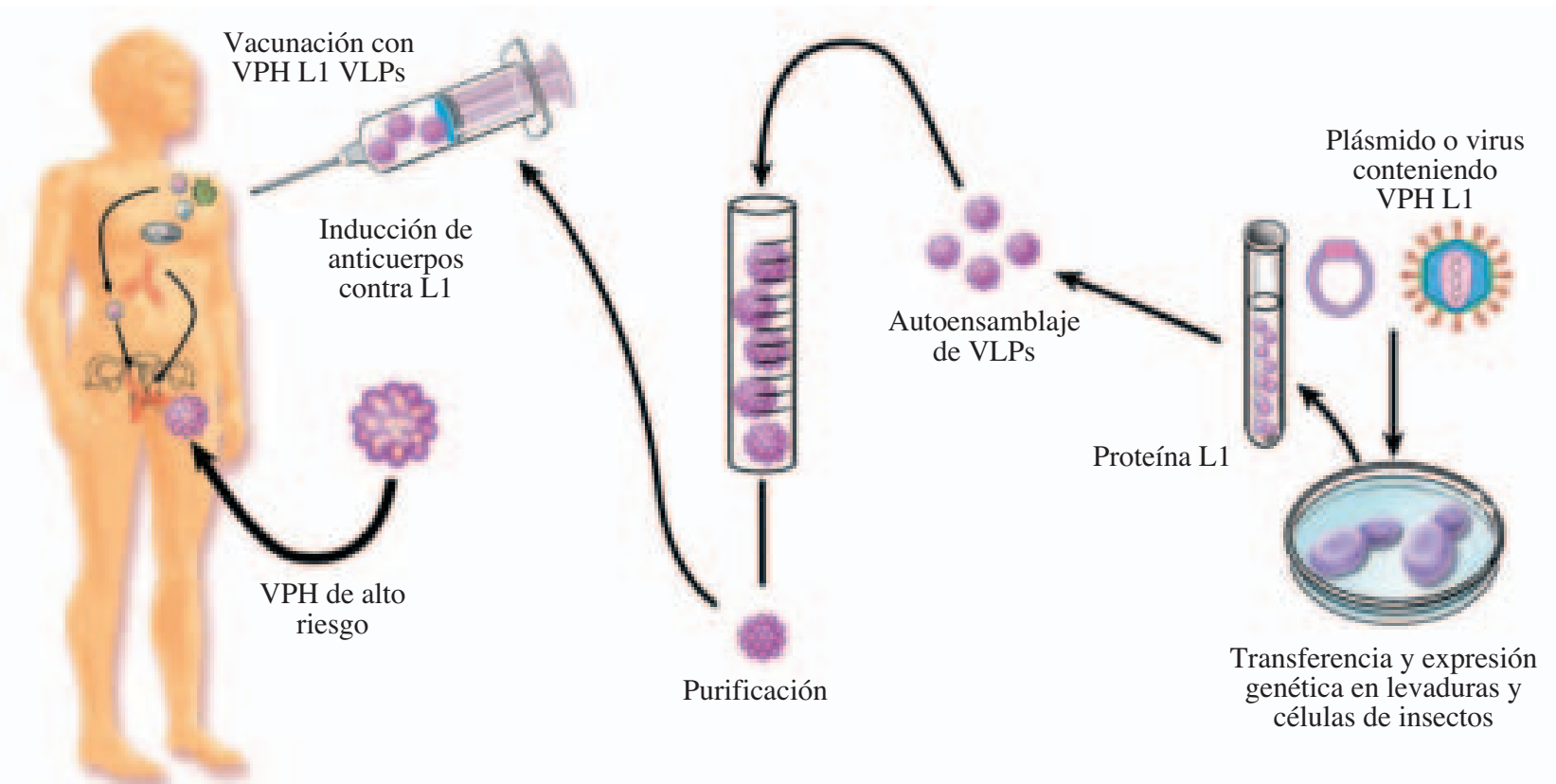

Figura 5. Síntesis de la vacuna profiláctica frente a VPH e inducción de inmunidad.

El proceso se realiza utilizando proteínas recombinantes L1 de la cápside de VPH (VLPs), que una vez sintetizadas y purificadas inducen en el sujeto vacunado inmunidad específica. Las células dendríticas presentan el antígeno (L1) a los linfocitos T helper y B. Éstos últimos se transforman en células plasmáticas que generan anticuerpos capaces de neutralizar el virus.

Fuente: Berzosky JA, et al. $2004^{134}$. Reproducido con autorización 
La protección cruzada frente a diferentes tipos virales tras la vacunación no está suficientemente demostrada ${ }^{98}$. En otros estudios, la inmunización frente a los tipos 16 y 18 mediante vacunación, protegería también frente a otros tipos virales como VPH 31,33 y $45^{83,86,88,90,95,99}$.

La vacuna bivalente VPH 16 y 18 administrada al $100 \%$ de la población, sólo podría prevenir el $65-70 \%$ de los cánceres genitales ${ }^{100,101}$. Si en la vacuna tetravalente de VPH 6, 11, 16 y 18 se incluyeran las proteínas frente a VPH 31, 45, 59 y otros, se podría alcanzar una prevención de carcinoma cervical en torno al 89-90\% 44, 47, 48, 82, 100, 101. Por la distinta prevalencia de tipos virales a nivel mundial, podrían generarse combinaciones de vacunas de VPH distintas, dependiendo de la población en la que se aplique el programa de inmunoprofilaxis $^{100}$.

Si con la vacunación se consiguiera erradicar los tipos virales más oncogénicos, podría producirse un desequilibrio mutagénico, potenciando los menos frecuentes. Son necesarios ensayos clínicos para determinar la prevalencia de los distintos tipos de VPH en poblaciones vacunadas y no vacunadas $^{2,47,49,102}$.

\section{Eficacia y seguridad}

La seguridad de las vacunas preventivas, tanto monovalentes como tetravalentes, se ha demostrado en ensayos con 20.500 pacientes comprendidas entre 16 y 26 años. Ambas presentan un porcentaje de eficacia cercano al $100 \%$ para prevenir lesiones precancerosas de cuello de útero, vulva o vagina, así como verrugas anogenitales en el caso de la tetravalente ${ }^{103,104}$. En un estudio multicéntrico realizado en EEUU y Brasil, se ha evidenciado que la vacuna profiláctica es segura, bien tolerada y altamente inmunogénica, en 1000 pacientes comprendidas entre 15 y 25 años. En el $92 \%$ de los casos fue efectiva en la prevención de citologías anormales y, prácticamente en el 100\% contra la infección persistente frente a VPH 16 y 18 y lesiones histológicas asociadas ${ }^{88,90}$.

Los resultados obtenidos en los estudios tras la vacunación tienen un seguimiento de 5 años. Hasta que no se confirme a largo plazo, la eficacia real de las vacunas contra VPH para prevenir el cáncer de cérvix es todavía hoy una incógnita ${ }^{81,83,89,90,91,103,105}$.

\section{Duración de la protección}

Demostrada la eficacia de la vacuna preventiva frente a VPH, el problema es que no se conoce la duración en el tiempo de esta protección. En el peor de los supuestos sería necesaria una dosis de recuer$\mathrm{do}^{89}$. Estudios en fase III demuestran tras la vacunación una seropositividad del $98 \%$ a los cuatro años y medio de seguimiento. Esto supone una prevención de la primoinfección por VPH del 98\%, y un $100 \%$ frente a la infección persistente ${ }^{23,88,90}$.

La exposición al virus postvacunación podría actuar como una dosis inmunológica de recuerdo natural, a la vista de estudios sero-epidemiológicos ${ }^{47,95,106}$.

La adición de un adyuvante como AS04 a la vacuna bivalente VLP L1 VPH 16/18, podría contribuir a incrementar la inmunogenicidad y su eficacia en el tiempo ${ }^{85,90}$.

En la actualidad no se conoce cuánto tiempo persiste la protección inducida por L1 VLPs, más allá de 4-5 años postvacunación ${ }^{47,49,52}$. Son necesarias más investigaciones para confirmar si la vacunación de recuerdo debe administrarse, a qué intervalos de tiempo y si realmente aporta beneficios ${ }^{2,83}$.

\section{Estrategias de vacunación profiláctica}

Numerosos trabajos en la literatura defienden la vacunación de ambos sexos, hombres y mujeres ${ }^{80}$, ${ }^{81,107}$. Aunque las secuelas de la infección por VPH en el hombre serían menos graves, especialmente en los varones heterosexuales, el sexo masculino es un importante vector de transmisión de la enfermedad. Por tanto, si se incluyeran en los programas de vacunación adolescentes y adultos varones, se produciría un incremento global de la inmunidad y una disminución de la incidencia de cáncer de cervix en la mujer y de verrugas y cáncer anal y genital en varones homosexuales ${ }^{44,49,50}$. Por otra parte, algunos estudios sugieren que podría existir una respuesta inmunitaria diferencial a la infección natural por VPH, según género. No hay datos concluyentes de la eficacia de la vacunación VPH frente a la prevención de la infección en varones ${ }^{2,83}$.

Según el estudio de Hughes sería necesario considerar la vacunación de ambos sexos a los 12 años de edad. Constata una disminución en la prevalencia de los tipos de VPH incluidos en la vacuna del $44 \%$, mientras que si sólo recibiera inmu- 
noprofilaxis el sexo femenino el descenso sería del $30 \%$ 52,91,102.

La relación coste/beneficio que supondría incluir en los programas de vacunación a los varones adolescentes, no justificaría el coste adicional comparado con la vacunación de mujeres exclusivamente. En efecto, si se vacunasen las adolescentes de 12 años, se reduciría el cáncer de cuello uterino en un $61,8 \%$, mientras que la vacunación masculina adicional sólo aportaría una reducción del 2,2\%, con un incremento del coste ${ }^{83,91,105}$.

La estrategia más efectiva comprendería la administración de la vacuna a niñas o adolescentes antes del inicio de la actividad sexual y de la exposición al virus VPH ${ }^{2,89,96,98,108,109,110}$. No obstante, quedaría por determinar la administración a adultos jóvenes no vacunados ${ }^{89,108}$.

En Diciembre de 2005, la Food and Drugs Administration (FDA) aprobó la licencia de la vacuna tetravalente en mujeres y hombres entre 9 y 15 años, y mujeres de 16 a 26 años de edad ${ }^{83,111}$. En 2006 se aprobó la vacuna bivalente ${ }^{89}$. Actualmente la vacuna frente a VPH está comercializada en América del Norte y en todos los países del Oeste de la Comunidad Económica Europea, a excepción de Italia y España ${ }^{112}$. En Noviembre de 2006 se entregó la propuesta al Sistema Nacional de Salud, en España, cuya resolución se espera para el segundo trimestre de 2007.

Para una adecuada campaña de vacunación contra el virus VPH, es imprescindible la implicación de los pediatras, así como los especialistas en ginecología y medicina familiar y comunitaria ${ }^{87,113,114}$. Paralelamente a la instauración del calendario vacunal, deberían llevarse a efecto campañas de divulgación sobre la prevención de VPH y los riesgos asociados a su transmisión ${ }^{52,115}$. Sería cuestionable si la prevención primaria frente a VPH modificaría los hábitos sexuales y la práctica segura del mismo ${ }^{116,117}$.

\section{Vacunación en países subdesarrollados}

Inicialmente, la vacunación frente VPH ofreció resultados muy alentadores para su implantación en los países subdesarrollados ${ }^{83,102,108,118}$. Pero muy pronto también surgieron limitaciones, puesto que es una vacuna de coste elevado, que requiere conservación en cadena de frío y precisa personal sanitario para su administración parenteral ${ }^{44,47,49,50,119}$. Se podrían sintetizar vacunas de segunda genera- ción, de menor coste y más estables a temperatura ambiental $^{96,120}$. Se encuentran en investigación otras vías de administración de la vacuna. La vía nasal o la administración oral serían alternativas fácilmente aplicables en los países del tercer mundo. Numerosos estudios están analizando la respuesta inmunológica en estos casos ${ }^{78,121-123}$.

La inmunidad frente a las vacunas VPH podría estar alterada en los pacientes inmunológicamente comprometidos (HIV, malaria endémica o hepatitis B). Esto supondría un factor limitante de la eficacia de la vacuna en países en vías de desarrollo. Son necesarios ensayos clínicos en esta población para determinar las limitaciones reales de la respuesta a la vacunación preventiva frente a $\mathrm{VPH}^{49}$.

\section{Cribado del cáncer de cuello uterino tras la vacunación}

Es preciso seguir detectando las lesiones precursoras y los cánceres invasivos asociados a otros tipos de VPH no incluidos en la inmunoprofilaxis, así como la patología que puede aparecer en mujeres no vacunadas o en las ya infectadas por el virus $44,49,87,101$.

El carcinoma de cervix es una enfermedad con un largo intervalo de tiempo entre la primoinfección por VPH y la presentación clínica neoplásica. Si se vacuna a las adolescentes antes de sus primeras relaciones sexuales, deberían transcurrir al menos diez años para demostrar una disminución de la incidencia de cáncer de cervix en la población general ${ }^{124,125}$. A largo plazo, los programas de cribado deberán ser modificados según consideraciones de coste-efectividad, aunque deberán mantenerse durante varias décadas desde la aplicación de la vacuna VPH a la población ${ }^{81,87,91,105,126}$.

Si la aplicación de la vacuna se incluye en las estrategias sanitarias poblacionales, se estima un descenso de un tercio o la mitad de SIL de alto grado en la población vacunada. El impacto en la reducción de lesiones de bajo grado será proporcionalmente inferior, pues sólo una minoría son causadas por los tipos virales incluidos en las vacunas VPH actuales $^{12,83,89,101,127}$.

Adicionalmente, si la vacuna fuera administrada a los grupos de población con menor acceso al sistema sanitario, podría prevenir la mayor parte de las infecciones no detectadas por ausencia de cribado ${ }^{83}$.

Por otra parte, si la vacunación disminuyera la 


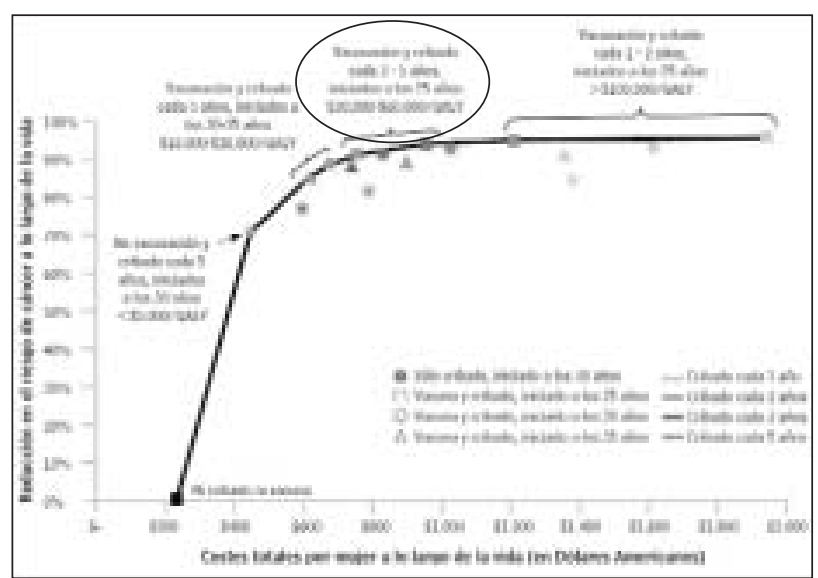

Figura 6. Coste-efectividad de diferentes estrategias de cribado de cáncer de cuello uterino y vacunación.

La mejor opción coste-efectividad sería vacunar a la población a los 12 años de edad e introducir el cribado citológico cada 5 años a partir de los 25 .

QALY: esperanza ajustada por calidad de vida.

Fuente: HPV Today (www.hpvtoday.com) ${ }^{68}$. Reproducido con autorización

prevalencia de la infección por VPH, el test de VPH podría sustituir eventualmente a la citología cervicovaginal como primer instrumento de cribado, en mujeres a partir de los 25 años de edad. La determinación de VPH ADN vería incrementada su especificidad y valor predictivo positivo, con la consecuente disminución de los costes y la posible modificación de los programas de screening ${ }^{2,128}$. Los nuevos protocolos posiblemente incluirán una combinación de inmunoprofilaxis y cribado de detección viral ${ }^{68,71,72}$ (Figuras 4 y 6).

\section{Vacunas terapéuticas frente a VPH}

El desarrollo de las vacunas terapéuticas frente a VPH, se ha llevado a cabo de forma mucho más lenta que el de las vacunas profilácticas ${ }^{47,49,83,86,129,}$ ${ }^{130}$. En un futuro próximo podrían suponer una nueva estrategia en el tratamiento del cáncer cervical. El objetivo sería erradicar o reducir el número de células infectadas por el virus ${ }^{83,96,131}$.

Las vacunas terapéuticas frente a VPH están constituidas por péptidos homólogos a determinadas proteínas virales, E6 y E777, 132. El péptido E7 origina inmunidad celular protectora frente a las displasias cervicales, previene crecimiento tumoral en modelos animales e induce respuesta anticuerpo-específica en el cáncer cervical en estadios ini- ciales $^{54}$. Una vacuna terapéutica eficaz sería aquella en la que los péptidos virales se unirían a las moléculas clase I de la superficie celular, induciendo una respuesta celular citolítica, fundamentalmente por estimulación de células T CD8, que podría destruir las células infectadas y eliminar la infección por $\mathrm{VPH}^{83,87,133}$.

Estas vacunas podrían ser aplicadas en aquellas pacientes en las que se hayan diagnosticado displasias, cánceres invasivos de cuello uterino, o como tratamiento adyuvante en recidivas o metástasis. El ensayo clínico de Berzosky estudia la eficacia terapéutica de la vacuna humana recombinante de virus VPH 16 y 18 E6 y E7, cuando se aplica en pacientes con carcinoma de cuello uterino recurrente o avanzado. La interpretación de los resultados es dificultosa, debido a que son pacientes que reciben también otros tratamientos ${ }^{134}$.

Una de las principales limitaciones de las vacunas terapéuticas es que actúan con distinta efectividad según el polimorfismo HLA que tenga el huésped, lo que supondría que en determinados pacientes vacunados no fuera tan eficaz ${ }^{54}$. Además, en pacientes con enfermedad avanzada existe una disminución de la respuesta inmunológica, por lo que la eficacia de la inmunoterapia estaría limitada ${ }^{135}$.

Los ensayos clínicos preliminares de vacunación terapéutica tratan de demostrar similar eficacia con respecto a los tratamientos actuales ${ }^{132,136}$. Probablemente la combinación de vacunas terapéuticas y otras terapias frente al cáncer de cuello uterino, como antivirales e inmunomoduladores, serán las opciones más a tener en cuenta en un futuro próximo ${ }^{137}$.

\section{Conclusiones}

El virus del papiloma humano representa la infección de transmisión sexual más frecuente, detectándose VPH de alto riesgo en prácticamente el 100\% de los casos de carcinoma escamoso de cérvix. La inmunidad humoral y celular contra la infección viral es crítica en el control y aclaramiento del VPH y, por tanto, en el desarrollo, persistencia y/o progresión de las lesiones displásicas.

Las vacunas preventivas frente a VPH están basadas en la producción de VLPs o partículas similares al virus. Existen dos tipos de vacunas para su aplicación en la prevención del cáncer de cuello uterino y otros 
cánceres genitales relacionados: la vacuna bivalente VPH 16 y 18 , y la tetravalente VPH $6,11,16$ y 18 , que protege también frente a los condilomas acuminados anogenitales. La pauta de administración son tres dosis intramusculares, generando una respuesta inmunológica específica a base de anticuerpos neutralizantes e inmunidad celular. El porcentaje de eficacia es cercano al $100 \%$. Se desconoce cuánto tiempo persiste la protección más allá de 4-5 años postvacunación, y si sería necesaria dosis de recuerdo.

La vacunación modificará los programas de screening respecto a la citología cervicovaginal. La nueva estrategia sería la combinación de inmunoprofilaxis primaria en la adolescencia y test de ADN VPH en el cribado de mujeres a partir de los 30 años de edad.

Aunque los resultados de los ensayos clínicos en fase III y IV sobre inmunización primaria son muy prometedores, deberemos esperar varias décadas de seguimiento para determinar la eficacia real de las vacunas profilácticas en la prevención de su objetivo principal: disminuir la incidencia de carcinoma de cuello uterino.

La vacuna preventiva frente a VPH será aprobada en los próximos 2 ó 3 años en la mayoría de los países desarrollados. En España probablemente será comercializada a lo largo del año 2007. Sería muy importante la disponibilidad de la vacuna en países subdesarrollados.

Las vacunas terapéuticas frente a VPH están constituidas por péptidos homólogos a las proteínas virales E6 y E7, y estarían indicadas en el tratamiento de displasias y cánceres invasivos de cuello uterino, o como terapia adyuvante en recidivas o metástasis. Como el desarrollo de las vacunas terapéuticas se encuentra aún en experimentación, el impacto de esta otra estrategia tardará en producirse. En cualquier caso, ya en este año y en las próximas décadas estaremos, sin lugar a dudas, ante uno de los descubrimientos más importantes de la medicina actual: la prevención y tratamiento de un cáncer mediante vacunación.

Correspondencia:

Dra. M. ${ }^{a}$ D. Diestro Tejeda

Servicio de Obstetricia y Ginecología

Hospital Maternal Universitario La Paz

Paseo de La Castellana, 261

E-28046 Madrid

mdtejeda@gmail.com

\section{Bibliografía}

1. Bosch FX, Lorincz A, Muñoz M, Meijer CJ, Shah KV. The causal relation between human papillomavirus and cervical cancer. J Clin Pathol 2002; 55: 244-265.

2. Lowndes CM. Vaccines for cervical cancer. Epidemiol Infect 2006; 134 (1): 1-12.

3. Ferlay J, Bray F, Pisan P, Parkin DM. GLOBOCAN 2002: Cancer incidence, mortality and prevalence worldwide. Lyon: IARC, 2004;147.

4. Bosch FX, Diaz M, De Sanjosé S, et al. Epidemiología de las infecciones por el virus del papiloma humano (HPV): riesgo de carcinoma cérvico-uterino y otros tumores anogenitales. Nuevas opciones preventivas. En: De Sanjosé S, García AM. $4^{\text {a }}$ Monografía de la Sociedad Española de Epidemiología. Virus del Papiloma Humano y Cáncer: epidemiología y prevención. Madrid: EMISA, 2006: 3150.

5. Miñarro R, Black RJ, Martínez C, Navarro C, Garau I, Izarzugaza I, et al. Cancer Incidence and Mortality in Spain- Patterns and Trends. IARC Technical Report $\mathrm{n}^{\circ}$ 36. Lyon: IARC, 2000; 27.

6. Parkin DM, Whelan SL, Ferlay J. Cancer Incidence in Five Continents. Vol III. IARC Scientific Publication $\mathrm{N}^{\circ}$ 155. Lyon: IARC, 2002; 27.

7. Bray F, Loos AH, McCarron P, et al. Trends in cervical squamous cell carcinoma incidence in 13 European countries: changing risk and the effects of screening. Cancer Epidemiol Biomarkers Prev 2005; 14: 677-86

8. De Sanjosé S. La investigación sobre la infección por virus del papiloma humano (VPH) y el cáncer de cuello uterino en España. En: De Sanjosé S, García AM. 4 Monografía de la Sociedad Española de Epidemiología. Virus del Papiloma Humano y Cáncer: epidemiología y prevención. Madrid: EMISA, 2006: 141-146.

9. Parkin DM. The global health burden of infection-associated cancers in the year 2002. Int J Cancer 2006; 118 (12): 3030-3044.

10. Koutsky L. Epidemiology of genital human papillomavirus infection. Am J Med 1997. 102: 3-8.

11. Syrjänen y Syrjánen. Papillomavirus infections in human pathology. Chichester: Wiley \& Sons, 2000; 117-141.

12. De San José S, Díaz M, Castellsagué X, Clifford G, Munoz N, Bosch FX. Worldwide prevalence and genotype distribution of cervical HPV DNA in 169-341 women from general population. A meta-analysis of the international literature. 2006 (enviado para publicación).

13. Molano M, Posso H, Weiderpass E, et al. Prevalence and determinants of HPV infection among Colombian women with normal cytology. Br J Cancer 2002; 87: 324-333.

14. Ferreccio C, Prado RB, Luzoro AV, et al. Population-based prevalence and age distribution of human papillomavirus among women in Santiago,Chile. Cancer Epidemiol Biomarkers Prev 2004; 13: 2271-2276.

15. Thomas JO, Herrero R, Omigbodun AA, et al. Prevalence 
of papillomavirus infection in women in Ibadan, Nigheria: a population-based study. Br J Cancer 2004; 90: 638645.

16. Forslund O, Antonsson A, Edlund K, et al. Populationbased type-specific prevalence of high-risk human papillomavirus infection in middle-aged Swedish women. J Med Virol 2002; 66: 535-541.

17. De San José S, Almirall R, Lloveras B, et al. Cervical human papillomavirus infection in the female population in Barcelona, Spain. Sex Transm Dis 2003; 30: 788-793.

18. Del Almo J, González C, Losana J. La infección por virus del papiloma humano en poblaciones a alto riesgo de cáncer de cuello uterino en España. En: De Sanjosé S, García AM. $4^{\text {a }}$ Monografía de la Sociedad Española de Epidemiología. Virus del Papiloma Humano y Cáncer: epidemiología y prevención. Madrid: EMISA, 2006: 71-88.

19. Múgica-Van Herckenrode C, Malcom AD, Coleman DV. Prevalence of human papillomavirus infection in basque Country women using slot-blot hybridization: a survey of women at low risk of developing cervical cancer. Int J Cancer 1992; 51 (4): 581-586.

20. Font R, Pérez M, Coll C, et al. Utilización de modelos longitudinales para estimar el tiempo de regresión/progresión de la infeccion por VPH en una cohorte de mujeres atendidas en centros de planificación familiar en Barcelona, España. Gac Sanit 2004; 18(3): 148.

21. Puig F, Echavarren V, Yago T, et al. Prevalence of HPV in a random simple o fan urban population in the city of Zaragoza (Spain). Prog Obstet Ginecol 2005; 48(4): 172178

22. González C, Ortiz M, Canals J, et al. Higher prevalence of HPV infection in migrant women from Latinoamerica in Spain. Sex Transm Infect 2006; 82: 260-262.

23. Woodman CB, Collins S, Winter H, et al. Natural history of cervical human papillomavirus infection in young women: a longitudinal cohort study. Lancet 2001; 357: 1831-1836.

24. Walboomers JM, Jacobs MV, Manos MM, et al. Human papilomavirus is a necessary cause of invasive cervical cancer worldwide. J Pathol 1999; 189(1): 12-19.

25. Clifford GM, Rana RK, Franceschi S, Smith JS, Gough G, Pimenta JM. Human papillomavirus genotype distribution in low grade cervical lesions: comparison by geographic region and with cervical cancer. Cancer Epidemiol Biomarkers Prev 2005; 14(5): 1157-1164.

26. Franco EL, Rohan TE, Villa LL. Epidemiologic evidence and human papillomavirus infection as a necessary cause of cervical cancer. J Natl Cancer Inst 1999; 91: 506-511.

27. Castellsague X, Muñoz N. Chapter 3: Cofactors in human papillomavirus carcinogenesis-role of parity, oral contraceptives and tobacco smoking. J Natl Cancer Inst Monogr 2003; (31): 20-28.

28. Castellsague X, Díaz M, De San José S, et al. The worldwide human papillomavirus etiology of cervical adenocarcinoma and its cofactors:implications for screening and prevention. J Natl Cancer Inst 2006; 98 (5): 303-315.
29. IARC Technical reports N3. Tabacco smoke and involuntary smoking. Lyon: IARC Press, 2004.

30. Anttila T, Saikku P, Koskela P, et al. Serotypes of Chlamydia trachomatis and risk of development of cervical squamous cell carcinoma. J Am Med Assoc 2001; 285:47-51.

31. Smith JS, Muñoz N, HerreroR, et al. Evidence for Chlamydia Trachomatis as a human papillomavirus cofactor in etiology of invasive cervical cancer in Brazil and the Philippines. J Infect Dis 2002; 185: 324-331.

32. Lehtinen M, Koskela P, Jellum E, et al. Herpes simplex virus and risk for cervical cancer: a longitudinal nested case-control study in the Nordic countries. Am J Epidemiol 2002; 156: 687-692.

33. Franco EL, Harper DM. Vaccination against human papillomavirus infection: a new paradigm in cervical cancer control. Vaccine 2005; 23: 2388-2394.

34. Manhart LE, Koutsky LA. Do condoms prevent HPV infection, external genital warts or cervical neoplasia? A meta-analisys. Sex Transm Dis 2002; 29: 725.

35. Castellsague X, Bosch FX, Muñoz N, et al. Male circumcision, penile human papillomavirus infection, and cervical cancer in female partners. N Engl J Med 2002; 346 (15): 1105-1112.

36. Trimble CL, Hildesheim A, Brinton LA, Shah KV, Kurman RJ. Hetereogenus etiology of squamous carcinoma of the vulva. Obstet Gynecol 1996; 87: 59-64.

37. Ishi K, Suzuki F, Saito A, Kubota T. Infect Prevalence of HPV, Chlamydia Trachomatis and Neisseria gonorrhoeae in commercial sex workwers in Japan. Infect Dis Obstet Gynecol 2000; 8: 235-239.

38. Juarez LA, Wheeler CM, Uribe-Salas FJ, et al. HPV: a hihgly prevalent sexualy transmited disease agent among female sex workers from Mejico City. Sex Transm Dis 2001; 28(3): 125-130.

39. Touzé A, De San José S, Coursaget P, et al. Prevalence of antihuman papillomavirus type 16, 18, 31 and 58 virus-like particles in women in the general population in prostitutes. J Clin Microb 2001; 39(12): 4344-4348.

40. De San José S, Valls I, Paz M, et al. HPV and human immunodeficiency virus infections as risk factors for cervix cancer in women prisioners. Med Clin (Barc) 2000; 115: 81-84.

41. Hemminki K, Dong C, Vaittinen P. Familiar risks in cervical cancer: is there a hereditary component? Int G Cancer 1999; 82: 775-781.

42. Ahdieh L, Klein RS ,Burk R, et al. Prevalence, incidence and type-specific persistence of HPV in HIV-positive and HIV-negative women. J Infect Dis 2001; 184: 682-690.

43. De Williers EM, Fauquet C, Broker TR, et al. Classification of papilomaviruses. Virology 2004; 324: 17-27.

44. Stanley MA. HPV vaccines: prospects for eradicating cervical cancer. J Fam Plann Reprod Health Care 2004; 30(4): 213-215.

45. Ortiz M, Torres M, García A. Determinación del virus del papiloma humano (VPH): aspectos técnicos. En: De San- 
josé S, García AM. 4ª Monografía de la Sociedad Española de Epidemiología. Virus del Papiloma Humano y Cáncer: epidemiología y prevención. Madrid: EMISA, 2006: 89-106.

46. Bosch FX, Manos MM, Muñoz N, et al. Prevalence of human papilomavirus in cervical cancer: a worldwide perspective. J Natl Cancer Inst 1995; 87: 796-802.

47. Stanley MA. Human papillomavirus vaccines. Rev Med Virol 2006; 16: 139-149.

48. Muñoz N, Bosch FX, De San José S, et al. International agency for research on cancer multicenter cervical cancer study group. Epidemiologic classification of HPV types associated with cervical cancer. N Engl J Med 2003; 348: 518-527.

49. Stanley MA. Inmune responses to HPV. Vaccine 2006; 1 : 16-22.

50. Stanley MA. Virus-keratinocyte interactions in the infectious cycle. En: Stern PL, Stanley MA. HPV and cervical cancer. Oxford: Oxford University Press, 1994; 116-131.

51. Oriel JD. Natural History of genital warts. BR J Vener Dis 1971; 47: 1-13.

52. Frazer IH, Cox JT, Mayeaux EJ, et al. Advances in Prevention of Cevical Cancer and Other Human Papillomavirus-Related Diseases. Pediatrics Infect Dis J 2006; 25 : S65-S81.

53. Chow LT, Broker TR. Mechanisms and regulation of papillomavirus DNA replication. En: Saveria Campo MS , editor. Papillomavirus research from natural history to vaccines and beyond. Norwich: Caister Academic Press, 2005; 53-71.

54. Padilla-Paz LA. Human Papillomavirus Vaccine: History, Inmunology, Current Status, and Future Prospects. Clin Obstet and Gynecol 2005; 48 (1): 226-240.

55. Elfgren K, Kalantari M, Moberger B, Hahmar B, Dillner J. A population-based five-year follow-up study of cervical HPV infection. Am J Obstet Gynecol 2000; 183: 561567.

56. Baseman JG, Koutsky LA. The epidemiology of human papillomavirus infections. J Clin Virol 2005; 32 (1): S16S24.

57. Khan MJ. The elevated 10-year risk of cervical precancer and cancer in women with HPV type 16 or 18 and the possible utility of type specific HPV testing in clinical practice. J Natl Cancer Inst 2005; 97: 1072-1079.

58. Castle PE, Solomon D, Schiffman M, Wheeler CM. HPV type 16 infections and 2-year absolute risk of cervical precancer in women with equivocal or mild citologyc abnormalities. J Natl Cancer Inst 2005; 97(14): 1066-1071.

59. Kjaer SK, Van der Brule AJ, Paull G, et al. Type specific persistente of high risk HPV as indicador of high grade cervical squamous intraepithelial lesions in young women: population based prospective follow up study. BMJ 2002; 325: 572.

60. IARC Working Group on evaluation of cervical cancer screening programmes. Screening for squamous cervical cancer: duration of low risk after negative results of cer- vical cytology and its implication for screening policies. Br Med J (Clin Res Ed) 1986; 293: 659-664.

61. Martin-Hirsch PL, Koliopoulos G, Paraskevaidis E. Is it now time to evaluate the true accuracy of cervical cytology screening? A review of the literature. Eur J Gynaecol Oncol 2002; 23: 363-365.

62. Grupo de cáncer de cuello uterino. Gonzalez Merlo J, Abad L, Balagueró L, et al. En: Documentos de consenso de la SEGO. Madrid: Editorial Meditext, 1997: 115-130.

63. Krane JF, Granter SR, Trask CE, Hogan CL, Lee KR. Papanicolaou smear sensitivity for the detection of adenocarcinoma of the cervix: a study of 49 cases. Cancer 2001; 93 (1): 8-15.

64. De San José S, Alejo M, Combalia N, et al. Historia del cribado en mujeres con cáncer infiltrante de cuello uterino. Gaceta Sanitaria 2006; 20 (2): 166-170.

65. Gálvez IM, González J, Lubián M. Cribado de cáncer de cérvix. A quién y cuéndo. Atención primaria 1998; 21 : 234-239.

66. Puig-Tintoré LM, De San José S, Méndez C, et al. Prevención secundaria: situación actual del cribado del cáncer de cuello uterino en España. En: De Sanjosé S, García AM. $4^{a}$ Monografía de la Sociedad Española de Epidemiología. Virus del Papiloma Humano y Cáncer: epidemiología y prevención. Madrid: EMISA, 2006: 131-140.

67. Bolick DR, Hellman DJ. Laboratory implementation and efficacy assessment of the ThinPrep cervical cancer screening system. Acta Cytologica 1998; 42 (1): 209-213.

68. HPV Today (versión española) $N^{\circ} 7$. HPV en 100 diapositivas. Madrid: Bypass Comunicación en salud, S. L. 2005; Octubre: 13. (http://www.hpvtoday.com).

69. Cox, Salomón, et al. ALTS followup. Am J Obstet Gynecol 2003; 1406-1410.

70. Ponce J. Cribado del cáncer de cuello uterino. En: Cabero L1, Iglesias X, Balagueró Ll, Xercavins J. XII Curso intensivo de formación continuada. Ginecología Oncológica. Madrid: Ediciones Ergón, S. A. 2005; 35-42.

71. Puig-Tintoré LM, Cortés J, Castellsague X, et al. Prevención del cáncer de cuello uterino ante la vacunación frente al virus del papiloma humano. Prog Obstet Ginecol 2006; 49 (2): 5-62.

72. Bosch FX, de Sanjosé S. Epidemiología de las infecciones por el virus del papiloma humano (VPH) y sus asociadas. En: Cabero Ll, Iglesias X, Balagueró Ll, Xercavins J. XII Curso intensivo de formación continuada. Ginecología Oncológica. Madrid: Ediciones Ergón, S. A. 2005; 7-14.

73. Ponce J, Vilata JJ. Infección por el virus del papiloma humano (VPH). Consejo multidisciplinar del Foro VPH. Prog Obstet Ginecol 2001; 44: 289-323.

74. Castellsagué X, Albero G, Martí D, et al. Prevención primaria: vacunas frente al virus del papiloma humano (VPH) para la prevención del cáncer de cuello uterino. En: De Sanjosé S, García AM. $4^{\text {a }}$ Monografía de la Sociedad Española de Epidemiología. Virus del Papiloma Humano y Cáncer: epidemiología y prevención. Madrid: EMISA, 2006: 107-130. 
75. Zhou J, Sun XY, Stenzel DJ, Frazer IH. Expression of vaccinia recombinant HPV $16 \mathrm{~L} 1$ and $\mathrm{L} 2 \mathrm{ORF}$ proteins in epithelial cells is sufficient for assembly of HPV virionlike particles. Virology 1991; 185 (1): 251-257.

76. Schiller JT, Lowy DR. Papillomavirus-like particles and HPV vaccine development. Semin Cancer Biol 1996; 7 (6): 373-382.

77. Xercavins J, Gil A, Centeno C. Virus y cáncer genital. En: Cabero L1, Iglesias X, Balagueró L1, Xercavins J. IX Curso intensivo de formación continuada. Ginecología Oncológica. Madrid: Ediciones Ergón S. A. 2002; 9-16.

78. Billich A. HPV vaccine MedImmune/GlaxoSmithKline. Current Opinión in Investigational Drugs 2003; 4 (2): 210-213.

79. Koutsky LA, Ault KA, Wheeler CM, et al. A controlled trial of a human papillomavirus type 16 vaccine. $\mathrm{N}$ Engl $\mathrm{J}$ Med 2002; 347: 1645-1651.

80. Lehtinen M, Paavonen J. Vaccination against human papilomaviruses shows great promise. Lancet 2004; 364 : 1731-1732.

81. Schiller JT, Davies P. Delivering on the promise: HPV vaccines and cervical cancer. Nat Rev Microbiol 2004; 2: 343-347.

82. Villa LL, Costa RL, Petta CA, et al Prophylactic quadrivalent human papillomavirus (Types $6,11,16$, and 18) virus-like particle vaccine in young women: a randomized double-blind placebo-controlled multicentre phase II efficacy trial. Lancet Oncol 2005; 6: 271-278.

83. Lowy DR, Schiller JT. Prophylactic human papillomavirus vaccines. J Clin Invest 2006; 116 (5): 1167-1173.

84. Kirnbauer R, Chandrachud LM, O’Neil BW, et al. Viruslike particles of bovine papillomavirus type 4 in prophylactic and therapeutic immunization. Virology 1996; 219 (1): 37-44.

85. Giannini SL, Hanon E, Moris P, et al. Enhanced humoral and memory B cellular inmunity using HPV 16/18 L1 VLP vaccine formulated with the MPL/aluminium salt combination (AS04) compared to aluminium salt only. Vaccine 2006; 24: 5937-5949.

86. Taff J. Overview: Vaccines against human papilloma viruses. Current Opinion in Investigacional Drugs 2006; 7 (8): 699-701.

87. Shaw AR. Human papillomavirus vaccines in development: If they're successful in clinical trials, how will they be implemented? Gynecol Oncol 2005; 99: S246-S248.

88. Harper DM, Franco EL, Wheeler C, Ferris DG, Jenkins D, Schuind A, et al. Efficacy of a bivalent L1 virus-like particle vaccine in prevention of infection with human papillomavirus types 16 and 18 in young women: a randomized controlled trial. Lancet 2004; 364 (9447): 17571765.

89. Steinbrook R. The Potential of Human Papillomavirus Vaccines. N Engl J Med 2006; (354): 1109-1112.

90. Harper DM, Franco EL, Wheeler CM, et al. Sustained efficacy up to 4.5 years of a bivalent L1 virus-like particle vaccine against human papillomavirus types 16 and 18 : follow-up from a randomised control trial. Lancet 2006; 367: 1247-1255.

91. Taira AV, Neukermans CP, Sanders GD. Evaluating human papillomavirus vaccination programs. Emerg Infect Dis 2004; 10: 1915-11923.

92. Emeny RT, Wheeler CM, Jansen KU, Hunt WC, Fu TM, Smith JF, et al. Priming of human papillomavirus type 11-specific humoral and cellular immune responses in college-aged women with a virus-like particle vaccine. J Virol 2002; 76 (15): 7832-7842.

93. Nardelli-Haefliger D. Specific antibody levels at the cervix during the menstrual cycle of women vaccinated with human papillomavirus 16 virus-like particles. J Natl Cancer Inst 2003; 95: 1128-1137.

94. Fife KH, Wheeler CM, Koutsky LA, et al. Dosseranging studies of the safety aand immunogenicity of human papillomavirus Type 11 and Type 16 virus-like particle vaccines in young healthy women. Vaccine 2004; 22: 2943 2952.

95. Orozco JJ, Carter JJ, Koutsky LA, Galloway DA. Humoral immune response recognizes a complex set of epitopes on human papillomavirus type 611 capsomers. J Virol 2005; 79: 9503-9514.

96. Galloway DA. Papillomavirus vaccines in clinical trials. Lancet Infect Dis 2003; 183: 561-567.

97. Ohlschlager P, Osen W, Dell K, et al. Human papillomavirus type $16 \mathrm{~L} 1$ capsomeres induce L1 specific cytotoxic CTL lymphocytes and tumour regression in C57BL/6mice. J Virol 2003; 77: 4635-4645.

98. Ho GY, Studentsov YY, Bierman R, Burk RD. Natural history of human papillomavirus type 16 virus-like particle antibodies in young women. Cancer Epidemiol Biomarkers Prev 2004; 13: 110-116.

99. Dubin G, Colau B, Zahaf T, Quint W, Martin M, Jenkins D. Cross-Protection against persistent HPV infection, abnormal cytology and CIN associated with HPV-16 and 18 realted HPV types by a HPV 16/18 L1 virus-like particle vaccine. Abstract $22^{\circ}$ International Papillomavirus Conference and Clinical Workshop, 30 abril-6 de mayo 2005Vancouver, Canadá.

100. Muñoz N, Bosch FX, Castellsague X, et al. Against which human papillomavirus types shall we vaccinate and screen?. The international perspective. Int J Cancer 2004; 111: 278-285

101. Clifford GM, Smith JS, Plummer M, et al. Human papillomavirus types in invasive cervical cancer worldwide: a meta-analysis. Br J Cancer 2003; 88: 63-73.

102. Hughes JP, Garnett GP, Koutsky L. The theoretical population-level impact of a prophylactic human papilloma virus vaccine. Epidemiology 2002; 13: 631-639.

103. Mao C, Koutsky LA, Ault KA, et al. Efficacy of human papillomavirus-16 vaccine to prevent cervical intraepithelial neoplasia: A randomized controlled trial. Obstet Gynecol 2006; 107 (1): 18-27.

104. Villa LL, Ault KA, Giuliano AR, et al. Immunologic responses following administration of a vaccine targeting 
human papillomavirus types $6,11,16$ and 18 . Vaccine 2006; 24 (27-28): 5571-5583.

105. Sanders GD, Taira AV. Cost-effectiveness of a potential vaccine for human papillomavirus. Emerg Infect Dis 2003; 9: 37-48.

106. Geijersstam V, Kibur M, Wang Z, et al. Stability over time of serum antibody levels to human papillomavirus type 16. J Infect Dis 1998; 177: 1710-1714.

107. Paavonen J, Halttunen M, Hansson BG, Nieminen P, Rostila T, Lehtinen M. Prerequisites for human papillomavirus vaccine trial: results of feasibility studies. J Clin Virol 2000; 19: 25-30.

108. Schiffman M, Castle PE. The promise of global cervicalcancer prevention. N Engl J Med 2005; 353: 2101-2104.

109. Winer RL, Lee SK, Hughes JP, Adam DE, Kiviat NB, Koutsky LA. Genital human papillomavirus infection: incidence and risk factors in a cohort of female university students. Am J Epidemiol 2003; 157: 218-226.

110. Family Health International. Reproductive health of young adults. 2003. Avalaible at: http://www.fhi.org/training/en/modules/ADOL/s1pg15.htm.

111. Merck \& Co Inc: Merck \& Co's Gardasil cervical cancer vaccine available in US. Press Release 2006: June 09.

112. Monsonego J. Cervical cancer prevention: the impact of HPV vaccination. Gynecologie, Obstetrique \& Fertilite 2006; 34 (3): 189-201.

113. Collins Y, Einstein MH, Gostout BS, et al Cervival cancer prevention in the era of prophylactic vaccines: a preview for gynecologic oncologists. Gynecologic Oncology 2006; 102 (3): 552-562.

114. Pichichero ME. Prevention of cervical cancer through vaccination of adolescents. Clinical Pediatrics 2006; 45 (5): 393-398.

115. Holcomb B, Bailey JM, Crawford K, Ruffin MT. Adults' knowledge and behaviors related to human papillomavirus infection. J Amn Board Fam Pract 2004; 17: 26-31.

116. Mays RM, Sturm LA, Zimet GD. Parental perspectives on vaccinating children against sexually transmitted infections. Soc Sci Med 2004; 58: 1405-1413.

117. De Melo-Martin I. The promise of the human papillomavirus vaccine does not confer immunity against ethical reflection. Oncologist 2006; 11 (4): 393-396.

118. Yang BH, Bray FI, Parkin DM, Sellors JW, Zhang ZF. Cervical cancer is a priority for prevention in different world regions: an evaluation using years of life lost. Int J Cancer 2004: 109: 418-424.

119. Denny L. The prevention of cervical cancer in developing countries. Intern Journal Obstetrics \& Gynaecology 2005; 112 (9): 1204-1212.

120. Yuan H, Estes PA, Chen Y, et al. Inmunization with a apentameric L1 fusion protein protects against papillomavirus infection. J Virol 2001; 75: 7848-7853.

121. Balmelli C, Roden R, Potts A, Schiller J, Grandi P, Nardelli-Haefliger D. Nasal inmunization of mice with human papillomavirus type 16 virus-like particles elicits neutralizing antibodies in mucosal secretions. J Virol 1998; 72 (10): 8220-8229.

122. Sasagawa T, Tani M, Basha W, et al. A human papillomavirus type 16 vaccine by oral delivery on L1 protein. Virus Research 2005; 110: 81-90.

123. Maclean J, Rybicki E, Williamson A. Vaccination strategies for the prevention of cervical cancer. Expert Rev Anticancer Ther 2005; 5 (1): 97-107.

124. Adams M, Borysiewicz L, Fiander A, et al. Clinical studies of human papilloma vaccines in preinvasive and invasive cancer. Vaccine 2001; 19: 2549-2556.

125. Peto J, Gilham C, Deacon J, et al. Cervical HPV infection and neoplasia in a large population-based prospective study: the Manchester cohort. Br J Cancer 2004; 91: 942-353.

126. Kulasingam SL, Myers ER. Potencial health and economic impact of adding a human papillomavirus vaccine to screening programs. JAMA 2003; 290: 781-789.

127. Pagliusi SR, Aguado M. Efficacy and other milestones for human papillomavirus vaccines introduction. Vaccine 2004; 23: 569-578.

128. Cuzick J, Szarewski A, Cubie H, et al. Management of women who test positive for high-risk types of human papillomavirus: the HART study. Lancet 2003; 362: 1871-1876.

129. Tomson TT, Roden RBS, Wu T-C. Human papillomavirus vaccines for the prevention and treatment of human cervical cancer. Curr Opin Investig Drugs 2004; 5 (12): 1247-1261.

130. Mahdavi A, Monk BJ. Vaccines against human papillomavirus and cervical cancer: promises and challenges. Oncologist 2005; 10 (7): 528-538.

131. Davidson EJ, Boswell CM, Sehr P, et al. Inmunological and clinical responses in women with vulval intraepithelial neoplasia vaccinated with a vaccinia virus encoding human papillomavirus 16/18 oncoproteins. Cancer Res 2003; 63: 6032-6041.

132. Jansen KU. Vaccines against cervical cancer. Expert Opin Biol Ther 2004; 4 (11): 1803-1809.

133. Da Silva DM, Kast WM. Vaccination against cervical cancer: hopes and realities. Am J Cancer. 2005; 4 (4): 207-219.

134. Berzosky JA, Jeffrey DA, Janik J, et al. Progress on new vaccine strategies against chronic viral infections. J Clin Invest 2004; 114 (4): 450-462.

135. Brinkman JA, Caffrey AS, Muderspach LI, Roman LD, Kast WM. The impact of anti HPV vaccination on cervical cancer incidence and HPV induced cervical lesions: consequences for clinical management. Eur J Gynaecol Oncol 2005; 26 (2): 129-142.

136. Corona CM, Tinoco A, Navarro T, et al. Therapeutic vaccination with MVA E2 can eliminate precancerous lesions (CIN 1, CIN 2 and CIN 3) associated with infection by oncogenic human papillomavirus. Human Gene Ther 2004; 15 (5): 421-431.

137. Stern PL. Recent developments in human papillomavirus vaccine. Expert Opin Investig Drugs 2004; 13 (8): 959971. 